\title{
Do Humano e da Técnica: Por uma Clínica da Pós-modernidade
}

Of Human and Technique : Towards a Clinic of Postmodernity

Del Humano y de la Técnica: Por una clinica de la Posmodernidad

\section{Ana Maria Szapiro}

Universidade Federal do Rio de Janeiro, Rio de Janeiro, RJ, Brasil.

\section{Resumo}

Este artigo examina os efeitos sobre o sujeito e sobre o fazer sociedade causados pela hegemonia da racionalidade tecnocientífica no contexto do ideário liberal das sociedades contemporâneas. Propondo uma clínica da pós-modernidade, destaca-se a emergência de um olhar objetivante sobre a condição humana, olhar que subtrai a singularidade que a constitui como ser da linguagem e da cultura. Predomina, deste modo, o discurso de que tudo é possível. Analisa-se, neste sentido, o surgimento de uma novilingua pós-moderna como dispositivo de constituição de uma visão pragmática e totalizante do homem e da vida coletiva.

Palavras chave: Sujeito; Psicanálise; Condição humana; Novilíngua; Pós-modernidade.

\begin{abstract}
This article examines the effects on the subjects and on making society caused by the hegemony of technoscientific rationality in the context of the liberal ideal of the contemporary societies. It propose a clinic of postmodernity highlighting particularly the emergence of an objectifying gaze on the human condition from which it subtracts the singularity that is like being of the language and culture. It predominates, nowadays the discourse that everything is possible. It also examines the emergence of a postmodern Newspeak in the constitution of a pragmatic and totalizing vision of man and collective life.
\end{abstract}

Key-words : Subject ; Psychoanalysis; Human condition; Newspeak ; Postmodernity

\section{Resumen}

Este artigo examina los efectos sobre lo sujeto y sobre el hacer sociedad causados por la hegemonía de la racionalidad tecnocientífica en el contexto de las ideas liberales de las sociedades contemporáneas. Por lo tanto, propone una clínica de la posmodernidad, destacando-se la emergencia de una mirada objetivante sobre la condición humana, mirada en la cual se substrae la singularidad que la constituye como ser del lenguaje y de la cultura. Predomina hoy el discurso 
de que todo es posible. También se examina el surgimiento de una nueva lengua posmoderna como dispositivo de constitución de una vision pragmática y totalizante del hombre y de la vida colectiva.

Palabras-clave: Sujeto; Psicoanálisis; Condición humana; Nueva lengua; Posmodernidad.

Os humanos são seres da linguagem, o homem é um parlêtre, disse Lacan (2007). Seres da linguagem, temos um corpo, que é biológico, mas cuja existência só pode ser expressa pela linguagem. Deste fato, nós, os humanos, habitamos um mundo diferente dos outros seres vivos, habitamos no mundo simbólico, este mundo que é feito de ilusões necessárias, que é refúgio e esperança para um viver possível e que o homem não cessa de inventar para lidar com a sua singularidade que é a de não ter uma natureza. Habitamos na cultura, habitamos a cultura...

Toda língua requer que estejamos permanentemente buscando atribuir um sentido ou dar “... uma mãozinha”, na expressão de Lacan ( 2007) para mantê-la viva. Por isto talvez as transformações de sentido das línguas sejam um lugar privilegiado de observação e de análise das épocas. Hoje constatamos, talvez mais do que em outra época, uma proliferação sem par de eufemismos, de deslocamentos semânticos, de transformações de sentidos de palavras e de expressões que apontam, que tornam evidentes as marcas da cultura contemporânea.
Estaríamos assistindo à fabricação de uma novilíngua, tal como Orwell (1949/2009) descreveu em sua obra 1984? Naquela obra Orwell cunhou o termo novilíngua referindo-se à emergência de nova linguagem, criada pelo governo totalitário da Oceânia de modo a permitir ao governo manipular a linguagem colocando-a a seu serviço. Isto acontecia fosse por meio da simples eliminação de palavras, fosse pela condensação de sentido, fosse pela criação de palavras novas. A novilíngua, ao produzir um rompimento entre a experiência e as palavras, seria um instrumento poderoso para o governo que, deste modo, visando controlar ideias e pensamentos, adquire então um poder total sobre a vida de todos em todas as suas dimensões.

A que propósito responderia hoje, nas sociedades democráticas contemporâneas, a novilingua emergente, senão ao assujeitamento a uma racionalidade tecnocientífica que se apodera da cultura ocidental? Esta novilingua vem decretar a inutilidade de todo saber oriundo do compartilhamento da experiência vivida entre as pessoas e entre as gerações e vem transformando a 
linguagem em instrumento de uma visão pragmática, de traços totalitários onde o que conta é, como argumenta Szapiro A. (2009), a dimensão de operacionalidade do conhecimento. Estamos empobrecendo, já observava Benjamin (1933/2012). Com a emancipação de uma racionalidade técnica e seu domínio, no qual a novilingua tem lugar fundamental, estamos eliminando o exercício da reflexão que é a linguagem, no final das contas, que torna possível. A linguagem nos coloca em relação uns com os outros, é na dimensão linguageira que percebemos o outro, que experimentamos o conflito e a pluralidade, a linguagem nos possibilitando estabelecer então uma relação entre as palavras e as ideias. Neste sentido, a novilíngua tecnocientífica, hoje maciçamente presente no cotidiano e nas trocas sociais, é parte de um processo de expropriação semântica e, por conseguinte, de eliminação da perspectiva da alteridade ao qual estamos hoje submetidos.

Klemperer (1947/2009) em sua obra “LTI A Linguagem do Terceiro Reich” analisou o papel da novilíngua na consolidação do regime nazista. Em suma, em ambos os contextos, seja na ficção 1984 de Orwell ( 1949/2009), seja na LTI, a novilíngua é uma linguagem que, criando uma impossibilidade e curto-circuitando a reflexão de ideias, vem produzindo a naturalização de enunciados que tomamos como verdades, revelan- do-se aí as tendências totalitárias que estão em curso na atualidade.

Mas não se trata de uma forma de totalitarismo marcado pela presença clara da figura de um tirano. Nossas sociedades democráticas globalizadas, são, ao mesmo tempo anti-totalitárias e neo-totalitárias, sublinha Dewitte (2007). Assim, o neo-totalitarismo, operando pela foraclusão da alteridade, pela exclusão ontológica da alteridade faz com que tudo que introduz a dimensão de alteridade, por supostamente ameaçar o consenso democrático seja neutralizado através de uma depuração da linguagem, onde o politicamente correto se impõe.

Esta novilíngua surge no cenário de um novo mundo flexível e mutante e vem se constituindo em poderoso dispositivo de normatização dos modos de vida, algo que $\operatorname{Muray}^{1}$ (2000) denominou de mondificação do mundo. A novilíngua é, neste sentido, o instrumento portador de valores que impõem, em nome desta união de toda a humanidade, o exercício de busca de consenso no debate de ideias. Todo desacordo tornou-se então uma expressão de perigo e ameaça ao consenso, uma alternativa a ser colocada em desuso. É neste sentido, destaca Muray, que assistimos nos últimos vinte anos à erradicação do princípio da contradição.

É certo que o ato de falar é sempre um novo começo, que a relação entre as palavras e as coisas está sempre em aberto. 
Mas a palavra, livre, não é o exercício de uma pura liberdade sem limites (Dewitte, 2007). A palavra se destina a transmitir um significado. A convicção atual quanto ao direito ilimitado de total liberdade onde tornamos mutantes os sentidos das palavras, corresponde a uma ruptura do laço social, que é uma marca da experiência totalitária. E, se a marcha tecnológica nos coloca falantes de uma novilingua que é a redução da língua à racionalidade das coisas, certamente isto faz com que os homens estejam diante da experiência da pobreza, naquele sentido que Benjamin (1933/2010) atribuiu ao empobrecimento humano da experiência partilhável. Ele diz: “... Que moribundos dizem hoje palavras tão duráveis que possam ser transmitidas como um anel, de geração em geração?” (p. 114). Como consequência, estamos hoje de uma dimensão reduzida da vida humana, que Agamben (1998) analisou como a dimensão da vida nua. A este respeito, Agamben nos remete à filósofa Hannah Arendt em sua grande obra O Sistema Totalitário (1951/1972), sublinha um aspecto importante no processo que conduz ao totalitarismo, qual seja a emergência de um sentimento de desolação que se torna uma experiência cotidiana em certas condições de vida marginais na sociedade como, por exemplo, a velhice. Para Arendt este sentimento surge como último recurso para se enfrentar um mundo onde ninguém mais é digno de fé, onde não se pode mais contar com ninguém, no qual cada um parece ter que construir sua identidade fora da relação com o outro. Este quadro está cada vez mais presente no mundo atual e é certamente um sintoma evidente das fraturas no laço social.

\section{Uma clínica da vida nua?}

A palavra clínica nos inscreve de imediato, no exercício da experiência com o outro. A clínica nos remete a um olhar para um outro. Neste contexto de transformação contínua dos sentidos das palavras, que assinalei acima, cabe então, por prudência, recorrer a uma breve etimologia da palavra, de modo a relembrar como herdamos esta palavra, desde Hipócrates, na Antiguidade Clássica.

No universo grego a clínica formava parte do universo das tékhnai. Consistia a clínica em uma tekhné clinikè, como técnica, era uma prática. Como destacou Vernant ((2002), foi apenas na época clássica que se deu a separação por completo entre as tékhnai e as práticas mágicas dos adivinhos e feiticeiros. As tékhnai passaram, então, a designar uma ação na phýsis, indicando, por oposição ao acaso e/ou à sorte, uma perícia, quer dizer, um saber adquirido pela aprendizagem. Mas mesmo na época clássica as tékhnai embora tenham se tornado laicas, um fato histórico consumado, estavam mui- 
to distante de se referirem à uma aplicação da ciência tal como as entendemos hoje. Constituíam-se antes em um sistema de habilidades práticas de modo que, no caso que aqui examinamos, as tekhné clinikè, correspondiam à atividade - técnica - de inclinar-se em direção àquele que sofre, ao inclinar-se sobre aquele que sofria a partir de um saber teórico sobre a natureza e sobre as causas das doenças. Esta clínica, no dizer de Hipócrates, referia-se à prática médica e se definia como uma atitude em direção a um outro, um gesto de inclinar-se para o outro. Assim, uma clínica da pós-modernidade traduziria então esta atitude, este propósito de nos inclinarmos, de nos voltarmos para examinar, com nossos olhares contemporâneos, a problemática da pós-modernidade.

Jean-François Lyotard (1979/2002) descreveu a condição pós-moderna como o surgimento de uma nova época que se caracterizou pelo desaparecimento, pelo esgotamento, pelo descrédito das grandes narrativas que fundaram tanto a época clássica como a época moderna. Com o descrédito das grandes narrativas emerge então uma época onde todas estas grandes narrativas foram colocadas em questão e substituídas por novas narrativas que não cessam de se produzir, mas que não parecem suficientemente capazes de suportar a condição de desamparo original humana. É o exame destas novas narrativas próprias à pós-moderRev. Polis e Psique, 2013;3(2):4-18 nidade o que pode nos permitir compreender algo a respeito dos impasses em que nos encontramos no mundo pós-moderno atual. Eis porque eu penso que se impõe, com urgência, empreendermos uma clínica da pós-modernidade.

No contexto das transformações da pós-modernidade emerge, disse Lyotard (1979/2002) uma nova sociedade de transparência comunicacional. O cenário pós-moderno, ele sublinha, é “essencialmente cibernético-informático e informacional" (p.viii), é um cenário de ruptura com qualquer ideal de busca da verdade através de um saber científico - verificável e comprovável- tal como os discursos sobre os ideais da modernidade tornando-se o saber de ordem eminentemente pragmática. Assim, todo o enquadramento metafísico daquela ciência clássica que, pelo menos até o século XVII opunha ciência e técnica considerando que cabia à ciência enunciar as leis do real tal qual ele é, entrou pouco a pouco em declínio e, diante dos valores formadores e caros ao pensamento moderno, emerge um novo discurso sobre o mundo no qual nada é, pois que as coisas estão sempre em transformação. Nesta perspectiva a ciência não mais se preocupará em enunciar as leis do que é. Toma lugar uma ciência pragmática que, articulando-se definitivamente às possibilidades abertas pelo desenvolvimento tecnológico que desponta na revolução in- 
dustrial do século XIX, faz nascer a tecnociência.

Na perspectiva de análise de Elias (1939/1993) este saber pragmático implica em um completo e radical abandono do processo civilizatório da modernidade. Elias apontava o controle das pulsões e o triunfo da razão como questões centrais no caminho do processo civilizatório. Uma vez libertos da noite medieval pela razão, os homens se abririam ao progresso e ao entendimento. A centralidade que o valor de progresso ocupava então no mundo moderno, está testemunhada nas artes em geral e na literatura de época, com inúmeros exemplos. Stefan Zweig (1982) assim comenta a este respeito: “... acreditávamos mais no Progresso do que na Bíblia, e este evangelho parecia irrefutavelmente demonstrado a cada dia pelos novos milagres da ciência e da técnica.”(p.17-19). Era para ele a "idade de ouro da segurança" e sua geração, observa ainda Zweig, acalentava o idealismo segundo o qual o progresso da humanidade se acompanharia de uma "ascensão moral". Foi esta expectativa de ascensão moral do homem que sucumbiu diante dos campos de extermínio nazista. Ali a razão mostrou-se incapaz de oferecer garantia contra o ato humano irreparável.

O desencanto com os valores da modernidade encontrou sua saída na concepção pragmática do mundo e de um viver e tem na constituição das sociedades tecnológicas atuais a sua melhor expressão. Neste sentido, o lugar central ocupado hoje pelo pragmatismo sustenta a perspectiva das tecnociências como resposta a este novo mundo em permanente transformação. $\mathrm{O}$ investimento nos poderes das descobertas tecnocientíficas corresponde, finalmente, aos velhos anseios de onipotência próprios à humanidade. Freud (1929/1974) os precisou com grande destaque dizendo: "Épocas futuras trarão consigo novos progressos talvez de magnitude inimaginável [...] e não farão senão aumentar sua semelhança com um deus" (p.112). A aposta em conquistas de riquezas sem limites corresponde perfeitamente ao surgimento do novo capitalismo sem limites, o capitalismo financeiro, onde a ausência de limites ressoa atingindo hoje todas as dimensões das economias da vida humana e do viver juntos. Duas problemáticas principais que examinarei a seguir se abrem então, ambas convergindo para a formação do grande sintoma da pós-modernidade: o mandamento que se enuncia, como bem sublinhou Mannoni (1979): “eu sei, mas mesmo assim...” (p.9).

\section{Eu sei, mas mesmo assim...}

Primeiramente a pós-modernidade, compreendida como a época marcada pelo absoluto descrédito e deslegitimação das 
grandes narrativas corresponde, observa Dufour (2009/2013), ao triunfo sem par da ideologia liberal. O autor assinala que o triunfo do liberalismo marca o ápice de um lento processo de inversão de toda a metafísica ocidental, processo que se iniciou na Europa no século dezessete. Neste sentido, este processo de inversão está articulado à passagem do capitalismo de produção para o capitalismo de consumo na forma com que conformou as sociedades de mercado do mundo ocidental nos tempos atuais. Uma das características importantes desta nova forma de capitalismo e que Boltanski e Chiapello (2009) denominaram "o novo espírito do capitalismo" é a ficção transformada em certeza no mundo em que vivemos de que tudo é possível, de que não há limite para que se realizem todos os sonhos mais ousados do homem. Tal ficção corresponde à uma recusa do princípio da realidade. Neste sentido, assistimos hoje ao seguinte paradoxo: embora hoje convencidos de que o crescimento sem limites tem limites, mesmo assim, insistimos em crescer ilimitadamente.

Aqui a referência à obra de Mannoni (1979) “La outra escena”, se faz obrigatória. Como ele observa, a elucidação dos problemas ligados às crenças é ponto de fundamental importância para a Psicanálise. No texto sobre o fetichismo, Freud (1927/1974) retoma o conceito de recusa, Verleugnung, Rev. Polis e Psique, 2013;3(2):4-18 déni em francês, conceito que aparece em outros textos anteriores e que Freud irá retomar na discussão sobre a crença e que, no quadro do fetichismo, é uma questão central. Trata-se de recusa e não de repressão. Recusa da realidade, precisemos. Então eu encontro no meu velho Vocabulário da Psicanálise (Laplanche,J. e Pontalis, J.-B., 1970) o vocábulo recusa (da realidade) que diz o seguinte: “... termo utilizado por Freud que consiste numa recusa pelo indivíduo de reconhecer a realidade de uma percepção traumatizante, essencialmente a da ausência de pênis na mulher..." (p. 562).

Como argumenta Mannoni (1979), na problemática do fetichismo trata-se da recusa do desmentido que uma realidade infringe a uma crença: o fetichista sabe que as mulheres não têm falo, mas, neste caso, o mesmo assim é, para ele, o fetiche. O mecanismo da Verleugnung é utilizado para outras crenças que, pela recusa, sobrevivem ao desmentido da realidade. O fato $-\mathrm{a}$ realidade - hoje é que chegamos ao limite da capacidade de crescimento do planeta, estando o homem em vias de esgotar definitivamente todos os recursos de que necessitaria para preservar a sua própria casa. Entretanto, mesmo assim, continuamos a sustentar o discurso do crescimento. Isto talvez nos diga alguma coisa sobre o modo como o pensamento ultraliberal estabelece, nos seus fundamentos, a ideia de que, em- 
bora a evidência de limites esteja colocada, entretanto e, mesmo assim... Não olhar no face a face o desmentido da realidade quanto à onipotência do discurso do crescimento sem limites, é ou não uma recusa àquilo que é da ordem do desmentido da realidade, ademais inerente até mesmo à condição humana, qual seja, sua finitude?

De forma alguma, tomo o fetichista como o tipo pós-moderno por excelência. Chamo atenção, entretanto, para a presença no pós-moderno deste mecanismo de recusa da realidade, do limite. A crença do direito de cada um a uma liberdade sem limites tal como se apresenta na pós-modernidade, quer dizer, do direito a uma liberdade que, sendo levada às últimas conseqüências, vem se colocar acima do bem comum, se sustenta pela recusa ao desmentido da realidade. Encontramos como traço marcante do sujeito pós-moderno a reivindicação do direito ao estado de liberdade, compreendido como instrumento de afirmação da "realização de si" através e apenas através de uma auto-emancipação com relação a tudo que possa funcionar como constrangimento à auto-realização.

Esta lógica de pensamento se apoia numa espécie de a priori onde se encontra a exigência de liberação pulsional. Traça-se aqui um quadro onde não haveria mais o que sublimar? Talvez estejamos frente a um sujeito que não se coloca qualquer indaga- ção sobre a verdade de si. Este novo sujeito estaria voltado tão somente à realização de si, não ao bem comum. Ele se pergunta sobre o valor de sua ação não para o mundo, mas para si mesmo, pois como assinala Lyotard (1979/2002): “O traço surpreendente do saber pós-moderno é a imanência a si mesmo" (p.100).

Neste sentido é que a recusa do desmentido da realidade implica, consequentemente, na recusa da indagação sobre a verdade, sobre a verdade do ser. Esta recusa que, pouco a pouco, resultou no abandono da busca da verdade em proveito da busca do que é útil, do que funciona, dos novos deuses da ciência, talvez seja o aspecto mais central, a marca maior desta subjetividade, deste "sujeito". Aqui o descrédito no valor da transmissão de uma experiência, de um saber como forma de ascese foi substituído pela busca de um conhecimento que deve ser útil, que se considera como uma tekhné, tão somente um meio de atingir um fim prático. Assim, o lugar do saber do projeto moderno, a esperança prometeica sobre o saber como emancipação do homem para um mundo melhor, reduz-se, neste novo mundo da mercadoria, ao seu aspecto meramente informacional, sempre mutável e de caráter imediato. A pós-modernidade é o elogio às sensações.

Os efeitos do descrédito sobre o saber transmitido se expressa num sem nú- 
mero de sintomas, dos quais um dos mais visíveis é o que se tornou lugar comum e que usamos denominar como a crise de autoridade. Interpretada a partir de diferentes perspectivas, esta crise vem produzindo consequências para vida coletiva. Zizek (2004) assinalou nesta crise a desintegração das estruturas tradicionais antes reguladoras da vida libidinal. Ele pergunta:

(...) Por que razão o declínio da autoridade paterna e dos papéis sociais e sexuais estáveis tem gerado novas angústias, em lugar de suscitar um Melhor dos Mundos onde os indivíduos engajados em um cuidado de si criativo se beneficiariam de um processo de permanente modificação e de reorganização de suas múltiplas identidades fluidas? (p.109)²

De fato, se a saída do patriarcado e de outras formas de servidão, que submetiam os homens num mundo onde estruturas tradicionais conformavam e delimitavam a vida libidinal, merece certamente ser festejada, a superação deste mundo não se faz sem problemas, como alguns parecem acreditar. Isto porque o abandono dos paradigmas fundadores da modernidade substituídos hoje pelo imperativo de um direito à liberdade sem limites como quer o discurso da ideologia ultraliberal talvez não aconteça sem danos.

O texto "O mal-estar na cultura" (Freud, 1929/1974) talvez seja, em toda a obra freudiana, o momento de toda a grande obra de Freud em que nos encontramos diante de uma descrição clara do dilema atual do mundo construído pelo homem. Talvez porque Freud o tenha escrito num momento, 1929-1930, em que, quem sabe, pressentiu que o sonho de um futuro melhor do marco civilizatório acalentado pelo espírito das luzes da modernidade começava a dar os primeiros sinais de ruir, tomando, logo em seguida, a forma do pesadelo totalitário nazista. Freud ali apresentou com todas as letras sua tese sobre a existência de um antagonismo irremediável entre as exigências pulsionais e as restrições impostas pelo processo civilizatório. Este antagonismo se revela através do mal-estar incontornável. Se para Freud (1929/1974) “... o propósito da vida é simplesmente o programa do princípio do prazer" (p.94), são tantas as fontes possíveis de sofrimento que a felicidade seria, para nós, seres humanos, tão somente, como ele assim nomeia uma "manifestação episódica" (p.94). Sendo a busca da felicidade o propósito da vida, tampouco podemos renunciar a alcançá-la. Eis o que é a nossa condição humana.

Questão para a Psicanálise, para a Filosofia e para as Ciências Humanas, o conflito entre pulsão e cultura é a síntese da problemática humana. Este conflito que acompanha a trajetória civilizacional a época pós-moderna se esforça por negar. Esta é, 
a meu ver, a questão que atravessa de ponta a ponta a cena pós-moderna conformando-se como sintoma - tal como Freud o definiu, ou seja, como o substituto de alguma coisa que não foi possível acontecer. A liberação pulsional, um imperativo nas subjetividades da ideologia liberal implica na absoluta recusa em aceitar o conflito entre a pulsão e a cultura. Isto quer dizer, como bem observou Castel (1995), que hoje nos tornamos mais interessados na busca de obter um gozo maior do que em ter um conhecimento mais profundo sobre nós mesmos. A recusa na buscar da verdade, o abandono do esforço que requer esta atitude, responde àquele imperativo que deposita na liberação pulsional a condição de realização do projeto de felicidade. Este projeto se traduz atualmente numa fuga para adiante, onde a técnica é o lugar onde estão depositadas todas as esperanças dos homens de superação dos seus limites, inclusive da sua própria condição de finitude.

A pós-modernidade promete, sobretudo, a liberação do homem de uma forma de prisão que se colocava num mundo onde prevalecia não o sentido prático das coisas, mas a pergunta sobre a verdade delas. Assim, a pós-modernidade quer abrir-nos as portas, anuncia que podemos ser livres para caminhar melhor, nos convida a brindar ao fim de toda a servidão. Penso que uma clínica da pós-modernidade deve propor-se a examinar este mandato subjetivo de liberação pulsional pós-moderna indagando seus efeitos quanto ao que nos institui como seres humanos e como seres da cultura.

A uma clínica da pós-modernidade se impõe interrogar. Interrogar o sentido de todas estas mudanças, para o sujeito e para o viver juntos. Indagar o sentido das atuais mudanças torna possível conhecer em que direção estamos caminhando e em que mundo queremos chegar. Uma clínica da pós-modernidade deve interrogar os dilemas humanos tal como se constituem mundo atual. Em outras palavras: porque estamos no interior de um processo de imensas transformações - Gauchet (2008) fala mesmo de mutações - impõe-se indagar sobre os efeitos destas transformações para o mundo simbólico que é o mundo onde os homens habitam.

A armadura pós-moderna se constituindo, sobretudo, na negação do conflito entre pulsão e cultura busca tornar possível contornar as restrições impostas pelo viver juntos de modo a atender às exigências pulsionais. Diante do mal-estar, por que não, entram em cena as próteses de todo o tipo de maneira a oferecer remédio para tudo... Não à toa, Roland Gori (2005) fala de "medicalização da existência”... 


\section{Fabricam-se não-sujeitos}

Constatamos hoje igualmente o surgimento de novas formas de violência que são claramente consequência do que Dufour (2009/2013) analisa como resultado do advento de um novo funcionamento psíquico que já assinalei acima, a liberação pulsional. Não é só a tentativa de negar o caráter incontornável do conflito entre os interesses da pulsão e os da cultura, como Freud (1929/1974) analisou. É agora a naturalização da ideia de que o homem é livre para dar curso às suas pulsões porque ele é, por natureza, um ser livre que não deve, por isto, submeter-se a qualquer constrangimento a esta natureza.

É o que assistimos hoje com razoável frequência: passagens ao ato onde a ausência de implicação com seu próprio ato, onde a ausência de submissão à lei, à diferença do outro, tomaram a vida cotidiana. Aumentam comportamentos de adição de todos os tipos e em todas as idades, inclusive na infância, alguns deles esforçando-se por ultrapassar até mesmo as leis mais básicas dos limites que estabelece a condição de finitude do corpo. Tornou-se possível alcançar-se, apoiando-se nas descobertas técnicas, padrões de estética, níveis de performance sem limite.

O aumento significante no consumo mundial de antidepressivos, inclusive para Rev. Polis e Psique, 2013; 3(2):4-18 uso pediátrico, o aumento do consumo das drogas da "felicidade", assim como a elevada prescrição de Ritalina para crianças portadoras de TDAH (transtorno de déficit de atenção e hiperatividade) - medicamento cujo consumo vai se tornando cada vez mais banalizado e demandado por um grande número de pessoas que se queixam de falta de atenção em geral - corresponde diretamente ao elevado número de transtornos descritos que engrossou tanto o DSM IV (Diagnostic and Statistical Manual of Mental Disorders, Manual Diagnóstico e Estatístico dos Transtornos Mentais), como a sua versão V, versão atualizada do mesmo manual. Ali estão classificados os transtornos que identificam medicamente as mais diferentes formas de sofrimento mental, fazendo a prosperidade das indústrias farmacêuticas através do enorme crescimento do mercado de consumo de medicamentos. Afinal a cada transtorno, o seu remédio. Sofrimento é sinônimo de transtorno.

De algum modo parece estarmos diante de uma espécie de contra-clínica. Na tekhné clinikè de hoje a indústria farmacêutica medicaliza a vida, fabricando sem cessar um número cada vez maior de transtornos, reunindo sintomas e transformando emoções e comportamentos em doenças para as quais evidentemente haverá sempre um medicamento. Assim vimos surgir nas últimas décadas a figura do portador 
de transtorno que assim é nomeado e que se auto-nomeia, que assim se reconhece. Identificando-se como um portador, o sujeito tem seu sofrimento compreendido como um mau funcionamento apenas, para o qual a medicação é o instrumento de correção que, libertando-o do sofrimento o devolverá ao mundo da normalidade.

Desta maneira, a clínica pós-moderna é a clínica que cala o sujeito, uma contra-clínica. Enunciado apenas na negatividade, objetivado no transtorno, esta clínica trata do sofrimento de um não-sujeito, de um não parlêtre. Estamos diante da ficção de um homem sem contornos, portanto, sem limites, de uma condição humana que está para além da contingência do sofrimento como marca humana. A descrição ampliada do diagnóstico de depressão tal como se apresenta no manual DSM-V, o Manual na sua $5^{\mathrm{a}}$ versão corresponderá, certamente, a um aumento maior ainda do consumo mundial de antidepressivos. No caso do diagnóstico de TDAH a expansão que assistimos hoje de tal diagnóstico e que se manifesta quase como uma nova epidemia da infância é, a meu ver, efeito do olhar desta contra-clínica que subtrai o sujeito. Não por coincidência, se na primeira versão do DSM datada de 1952 foram classificadas 106 patologias, o mesmo manual apresenta na sua versão atual 410 distúrbios mentais!
Numa análise interessante sobre as questões que se abrem neste cenário de fabricação de doenças e de medicalização da existência, Diener ${ }^{3}$ (2011) chama atenção para a convergência dos interesses da indústria farmacêutica, dos grandes grupos médicos que utilizam os tratamentos, das agências de publicidade, das revistas científicas e poder público que divulgam as novas doenças. Trata-se agora de uma verdadeira epidemia de diagnósticos para todas as formas singulares do viver.

A narrativa pós-moderna, ao recusar o caráter conflito entre os interesses pulsionais e os da cultura prometendo libertá-lo da finitude e do sofrimento que atormenta os homens (Legendre, 1996) os instala numa subjetividade que sustenta a crença de que o sofrimento não precisa mais ser uma contingência do humano. Deste modo o sofrimento torna-se, assim, exteriorizado e objetivado, o que produz uma clínica eminentemente tecnicista, que nega a dimensão do simbólico como dimensão constitutiva da condição humana. Mas, como assinalou Lacan (1953) no Discurso de Roma, se o ser se constitui do simbólico, esta clínica que cala o sujeito é a clínica da vida nua, tal como Agamben (1998) conceituou a vida nua, a zoé dos gregos, esta vida comum a todos os seres vivos.

Confrontarmos esta concepção que reduz a vida humana à vida nua, significa 
nos colocarmos a tarefa de examinar suas consequências, empreendendo uma crítica. E isto só se torna possível se não renunciamos à uma reflexão profunda e permanente sobre que mundo estamos construindo, se, enfim, exercitamos uma clínica da pós-modernidade... Como disse Legendre (1996):

Fabricar o homem é colocar em cena a idéia do Pai, orientar os filhos de um e de outro sexo ao Interdito. O pai... é inicialmente uma questão simbólica, uma coisa teatral, o artifício vivo que frustra a sociedade dos sociólogos e a ciência dos biólogos... Vir ao mundo não é apenas nascer para seus pais, é nascer para a humanidade (p.23).

\section{Notas}

1 Muray, P. Désaccord parfait. Paris: Gallimard, 2000. O autor se refere assim à homogeneização do mundo, aquilo que corresponderia à uma normatização, por indiferenciação, dos modos de viver e de pensar, efeito da experiência inédita da globalização da economia e das culturas.

2 Tradução livre para Zizek (1974): “... Pour quelles raisons le déclin de l'autorité paternelle et des rôles sociaux et sexuels stables génère-t-il de nouvelles angoisses, au lieu de susciter um Meilleur des Mondes ... où les individus engagés dans un « souci de soi » créatif bénéficiraient d'un processes permanent de modification et de réorganisation de leurs multiples identités fluides ?» (p. 109).

${ }^{3} \mathrm{O}$ autor menciona a declaração do químico Karl Pfizer - pioneiro do marketing farmacêutico e que se tornou líder do mercado por ter comercializado o medicamento Prozac - segundo a qual "é preciso criar doenças.”.

\section{Referências}

Agamben, G. (1998) O Poder soberano e a Vida nua. Portugal: Editorial Presença.

Arendt, H.(1951/1972) Le système totalitaire. Paris : Éditions du Seuil. (Obra original publicada em 1951).

Benjamim, W. (2010) Experiência e Pobreza. In Benjamin, W. Obras Escolhidas (pp.114-119). São Paulo: Editora e livraria Brasiliense. Trabalho original publicado em 1933.

Castel, R. (1987) A gestão dos Riscos Da antipsiquiatria à pós-psicanálise. Rio de Janeiro: Livraria Francisco Alves Editora. Obra original publicada em 1981.

Dewitte, J. (2007) Le pouvoir de la langue et la liberté de l'esprit. Essai sur la résistance au langage totalitaire) Paris: Editions Michalon.

Dufour, Dany-Robert (2013). A Cidade Perversa liberalismo e pornografia. 
Rio de Janeiro: Civilização Brasileira. Obra original publicada em 2009.

Diener, Y. (2011) On agite un enfant. L'État, les psychothérapeutes et les psychotropes. Paris: La fabrique éditions.

Elias, N. (1993) O processo civilizador. Rio de Janeiro: Jorge Zahar Ed. Obra original publicada em 1939.

Freud, S. (1974) Fetichismo. Edição standard brasileira das obras completas de Sigmund Freud (J. Salomão trad., Vol.XXI pp.179-185). Rio de Janeiro: Imago. (trabalho original publicado em 1927).

Freud, S. (1974) O mal-estar na cultura. Edição standard brasileira das obras completas de Sigmund Freud (J. Salomão trad., Vol.XXI pp.75-254). Rio de Janeiro: Imago. (trabalho original publicado em 1929).

Gauchet, M. (2008) L'impossible entrée dans la vie. Bruxelles, Yapaka.

Gori, R. Del Volgo,M-J. (2005) La Santé Totalitaire. Paris: Denoël.

Klemperer, V. (2009) LTI A Linguagem do Terceiro Reich.Rio de Janeiro: Contraponto. Trabalho original publicado em 1947.

Lacan, J. (1966) Fonction et champ de la parole et du langage en psychanalyse.
In: Lacan, J. Écrits (pp. 237-322). Paris: Seuil.

Lacan, J. (2007) Seminário 23: O sinthoma. Rio de Janeiro: Jorge Zahar.

Laplanche, J.; Pontalis, J-P. (1967). Vocabulário de Psicanálise. (Tamen, P. trad.). Portugal: Martins Fontes.

Legendre, P. (1996) La fabrique de l'homme occidental. Paris: Ed. Mille.et.une. nuits.

Lyotard. JF. (1979/2002) A condição Pósmoderna. Rio de Janeiro: Ed. José Olympo

Mannoni, O. (1979) La otra escena. Claves de lo imaginario. Buenos Aires: Amorrortu editores S.A.

Muray, P. (2000) Désacord parfait. Paris: Gallimard.

Orwell, G. (2009) 1984. Rio de Janeiro: Companhia das Letras. Trabalho original publicado em 1949.

Szapiro, A. (2009) O imperativo da utilidade, a hegemonia da técnica e seus efeitos sobre o humano. In: Szapiro, A. Clínica da pós-modernidade, formas de subjetivação, de violência e de dessimbolização. ( pp.79-92) Rio de Janeiro: Ed. Bapera.

Vernant, J.P. (2002) Mito \& pensamento entre os gregos. Rio de Janeiro: Ed. Paz e Terra. 
Zizek,S. (2004) Plaidoyer en faveur de l'Intolerance. Castelnau-le-Lez, Edition Climats.

Zweig, S. (1982) Le monde d'hier. Paris: Belfond, Ed. Poche, 1982.

Ana Maria Szapiro: Graduada em Psicologia pela Universidade Federal do Rio de Janeiro, psicanalista, Mestre em Psicologia Clínica pela Pontifícia Universidade Católica do Rio de Janeiro,PUC-Rio.

Doutora em Psicologia pela Pontifícia Universidade Católica do Rio de Janeiro, PUC-Rio.

Pós-doutora pela Université Paris VIII.

Professora associada na Universidade Federal do Rio de Janeiro/UFRJ no Instituto de Psicologia e professora colaboradora no Programa de pós-graduação em Psicossociologia de Comunidades e Ecologia Social, EICOS/ UFRJ.

Maître de Conférences na Université Paris VIII no Département des Sciences de l'éducation nos anos de 2003, 2007 e 2010.
Membro do Núcleo de Formação da Escola de Saúde Mental, ESAM/RJ.

Como pesquisadora, tem se dedicado à investigação da problemática do sujeito na pós-modernidade, coordenando o Projeto "Corpo, Sujeito e Servidão" projeto que integra o Grupo de Pesquisa CULTURA CONTEMPORÂNEA: Subjetividade, Conhecimento e Tecnologia registrado no Diretório dos Grupos de Pesquisa do CNPq do qual é uma das líderes.

Membro do Grupo de Pesquisa QUALIDADE DO LUGAR E PAISAGEM/ CNPq.

Membro associado do Grupo de Pesquisas PAIDEIA/ PARIS VIII, ligado à École Doctorale Disciplines du Sens, coordenado por Dany Robert Dufour, filósofo e professor do Département des Sciences de 1' éducation da Université Paris VIII Vincennes-St. Denis, França.

E-mail: anaszapiro@uol.com.br

Recebido em: 11/12/2013 - Aceito em: 25/02/2014 